\title{
Concerns, Knowledge, and Efficacy: An Application of the Teacher Change Model to Data Driven Decision-Making Professional Development
}

\author{
Karee E. Dunn ${ }^{1 \#}$, Denise T. Airola ${ }^{2}$, Mickey Garrison ${ }^{3}$ \\ ${ }^{1}$ Eleanor Mann School of Nursing and Educational Statistics and Research Methods, \\ University of Arkansas, Fayetteville, USA \\ ${ }^{2}$ Office of Innovation for Education, University of Arkansas, Fayetteville, USA \\ ${ }^{3}$ Director of Data Literacy, Oregon Department of Education, Salem, USA \\ Email: "kedunn@uark.edu
}

Received July $18^{\text {th }}$, 2013; revised August $18^{\text {th }}, 2013$; accepted August $26^{\text {th }}, 2013$

\begin{abstract}
Copyright (C) 2013 Karee E. Dunn et al. This is an open access article distributed under the Creative Commons Attribution License, which permits unrestricted use, distribution, and reproduction in any medium, provided the original work is properly cited.
\end{abstract}

\begin{abstract}
The purpose of this theoretical and qualitative work was two-fold. First, the Triadic Change Model (TCM) was presented and explained. Second, the TCM was used to develop an assessment framework in order to evaluate teachers' status in the change process associated with the adoption of Data Driven DecisionMaking (DDDM) in the United States. One dominant profile emerged through the use of the TCM assessment framework. In this profile, teachers manifested concerns indicating they were reluctant to engage in DDDM, held moderate efficacy for DDDM, experienced moderate levels of anxiety associated with DDDM, and showed low levels of knowledge required for effective DDDM. Research-based recommendations for practice and future research are discussed for this profile.
\end{abstract}

Keywords: Efficacy; Concerns; Anxiety; Data Driven Decision-Making

\section{Introduction}

The purpose of the present work was two-fold. First, the Teacher Change Model (TCM), its theoretical foundation, and the TCM assessment framework are presented. Then, the resultant qualitative analysis was based on the TCM assessment framework outcomes. The findings presented here were used to drive a successful statewide data driven decision-making (DDDM) initiative (Airola \& Dunn, 2011). It is important to note that while this study was completed in the US, the push for the use of data to drive instruction as well as the obstacles to achieve that goal reaches beyond the borders of the US to many other nations (Espin, McMaster, Rose, \& Wayman, 2012; Schildkamp \& Kuiper, 2010).

In the US, the federal push for Data Driven Decision-Making (DDDM) in schools has not subsided, but teachers continue to feel threatened by the concept and remain as unprepared to engage in DDDM as they have been since No Child Left Behind (NCLB) legislation was passed in 2001 (Samuel, 2008; Wayman, 2005). Many teachers either do not use data at all or only trust data to confirm their intuition, rather than using data to shape decision-making (Ingram, Louis, Schroeder, 2004). Wayman and Stringfield (2006) stated it well when they noted that, "the notion of involving teachers in data use is easier said than done" (p. 2). This issue has resulted in the development of a paradox in the DDDM literature. More specifically, a great

\footnotetext{
*This research was completed as a part of a project funded by the Oregon Department of Education.

\#Corresponding author.
}

deal of researches investigate the impact of DDDM on student outcomes, but very few research investigates the change process related to teacher adoption of DDDM (Dunn, Airola, Garrison, \& Nickens, 2011; Mandinach, 2011). This is an unfortunate gap in the literature as teachers are critical change agents in enacting any educational reform (Beck, Czerniak, \& Lumpe, 2000).

Research indicates that DDDM is effective at improving student outcomes (Airola \& Dunn, 2011; Carlson, Borman, \& Robinson, 2011; Scheurich \& Skrla, 2003), but the bulk of researches on the force that leads to classroom level data useteachers-primarily focus on these change agent's lack of requisite knowledge and skills for DDDM. This literature fails to explicate how to create a data-literate faculty (Bernhardt, 2009; Creighton, 2007; Kerr, Marsh, Ikemoto, Darilek, \& Barney, 2006; Wayman, 2005). Stiggins (2001) defined data-literate faculty as possessing two skill-sets: 1) the ability to access and gather dependable, high-quality student data, and 2) the ability to use data to amplify student achievement. The purpose of the current work was to begin to better understand teacher adoption of DDDM through the lens of the TCM and to open the research conversation with regard to gap in the literature pertaining to creating a data-literate faculty.

The current research grew out of work with a Pacific Northwestern state invested in creating a data-literate faculty. The authors developed an assessment framework rooted in the TCM for interpreting the impact of DDDM professional development (PD) on teacher adoption of DDDM practices. The qualitative 
interpretation of the assessment framework outcomes resulted in the identification of a profile of teachers in the early stages of the change process associated with becoming data-literate and adopting DDDM. Furthermore, the TCM assessment framework provided a means to support the development of recommendations that facilitated teacher change through professional development. Ingram and her colleagues (2004) noted that even teachers in their sample of schools who were deemed to be advanced in data use were "dismissive of externally generated achievement data" and that this "is a cultural trait that teachers learn and pass on to other teachers as the 'right way' to think, act, and feel about the use of data" (p. 1273). The TCM and related assessment framework provide a lens through which to assess and interpret this cultural issue and to drive change.

\section{Theoretical Framework}

The TCM was influenced by a number of theories. Of primary influence was Bandura's (1978) social learning theory. In addition to this overarching theory, Hall, Wallace, and Dossett's (1973) Concerns-Based Adoption Model (CBAM), Ajzen's Theory of Planned Behavior (Ajzen, 1991), and Ohlhausen, Meyerson, and Sexton's (1992) Efficacy-Based Change Model (EBCM) influenced this work. The TCM represents an integration of various components of these theories, related research, and work with PD. The TCM incorporates three constructs from the various theories in a new configuration of interlocking determinants - concerns, efficacy, and knowledgeintended to guide PD and to predict behavior.

\section{Social Learning Theory}

The purpose of the TCM is to uncover the link between training and practice - in other words, to elucidate causal influences on teacher adoption of new behaviors. Through the lens of social learning theory, causal processes are explained in terms of reciprocal determinism in which behavior, cognition, and environment mutually influence one another (Bandura, 1978). Bandura incorporated a self-system within the cognitive component of reciprocal determinism consisting of cognitive structures and cognitive subfunctions for perception, evaluation, and behavior regulation. This self-system serves as the foundation for the TCM and each of the theories upon which the TCM draws.

\section{Concerns-Based Adoption Model}

The CBAM is an example of a theory that addresses the selfsystem described by Bandura. The CBAM is an empirically based conceptual framework that describes, explains, and predicts probable teacher behavior based upon relevant concerns as a teacher participates in developmental activities and implements an innovation (Hall \& Hord, 2011). Within this framework the Stages of Concern assesses concerns, which are an emotional response to an educational innovation (Hall \& Hord, 1987). More specifically, concerns reflect an individual's set of feelings, perceptions, preoccupations, thoughts, considerations, motivations, satisfactions, and frustrations related to a target innovation. Concerns follow a developmental pattern described as seven Stages of Concern and measured via the Stages of Concern Questionnaire (SoCQ) (Hall, George, \& Rutherford, 1979). The first stage, Unconcerned (Stage 0), indicates how highly the respondent prioritizes the innovation. In Stage 0 , the individual may be unaware of the innovation, or the teacher may be aware of, but unconcerned with the innovation.

Three categories of concerns encapsulate the remaining six stages: Self, Task, and Impact concerns. Self Concerns include two stages: Informational (Stage 1), and Personal (Stage 2). In Stage 1 , the individual expresses general awareness of and interest in the innovation, but requires more information about the innovation. In Stage 2, the individual expresses concerns about how the innovation will affect him or her and manifests concerns related to personal ability, adequacy, demands, and role.

Task concerns include stage of concern, Management (Stage 3 ), in which the individual expresses concerns about issues such as logistics and efficient resource allocation. The more mature or Impact Concerns include last the three stages: Consequence (Stage 4), Collaboration (Stage 5), and Refocusing (Stage 6). In Stage 4, the individual expresses concerns related to student outcomes. In Stage 5, the individual expresses concerns related to working others to increase the impact innovation. In Stage 6, the individual expresses concerns about modifying the innovation. Concerns profiles can be created with the use of the SoCQ. One may interpret where a group or individual is situated in the change process, predict the likelihood of engagement in relevant behaviors, or diagnose impediments to training in order to plan for implementation facilitation interventions (George, Hall, \& Stieglebauer, 2006).

Research indicates that teachers' concerns are malleable and affect the likelihood that teachers will adopt reform-related beliefs that later encourage reform-related behaviors (Sztajn, 2003). Thus, assessing an individual's intensity of concerns may be useful when evaluating the extent of implementation of an innovation such as a new educational practice. By identifying teachers' concerns regarding the adoption of new innovations, those charged with developing and delivering teacher PD may better achieve these goals. Therefore, concerns were incorporated into the TCM.

\section{Theory of Planned Behavior}

The TPB attempts to predict behavior based upon one's intention to perform, which is the product of attitudes, subjective norms, and perceived behavioral control (Ajzen, 1991). Similar to the TPB, the TCM examines what Ajzen (1991) describes as attitudes, subjective norms, and perceived behavioral control. However, the TCM does so in a unique manner by assessing teacher affect, motivation, and cognition.

With regard to teacher affect, the TCM examines teacher concerns. Because concerns include a teacher's or a group of teachers' feelings and attitudes toward an innovation or a behavior, teacher concerns mirror components of Ajzen's (1991) model (i.e., attitudes and subjective norms). Ajzen's (1991) also asserted that perceived behavioral control is equitable to efficacy, teacher perception of innovation-specific efficacy is assumed to assess this variable in the TCM. Further, the TCM incorporates knowledge, which is only tangentially and minimally included in the TPB. Teacher knowledge also influences teachers' perception of their control over a given behavior. If a teacher lacks the requisite knowledge or skills to engage in a behavior, they are less likely to engage in that behavior. This heuristic holds true for teacher DDDM as well (Dembosky, Pane, Barney, \& Christina, 2005). 


\section{Efficacy-Based Change Model}

The EBCM draws on three areas of research: concerns, selfbeliefs (efficacy, outcome expectancy, and outcome value), and attributional beliefs (Ohlhausen et al., 1992). Similar to the CBAM, the EBCM model assumes that the change process is idiosyncratic while also following a general developmental pattern. The EBCM views the change process, in part, as the product of the influence of efficacy beliefs (general and teacher efficacy) and attributional beliefs on individual's concerns.

Although the EBCM does include two components examined by the TCM, motivation via efficacy and attributions as well as affect via concerns, it fails to directly measure individuals' knowledge. While one may argue that the model indirectly measures individuals' perception of their knowledge, measures of perceived knowledge may greatly vary from actual knowledge (Cunningham, Zibulsky, \& Callahan, 2009). The TCM incorporates the role of motivation and affect in the change process and extends this model to include actual knowledge.

A further distinction between the TCM and the EBCM is that the TCM does not directly include one's attributions because the authors viewed efficacy as an indirect measure of attributions. This decision is supported by findings from multiple lines of research that indicate individuals' with a high sense of efficacy are more likely to attribute failures to things such as low levels of effort or unfavorable circumstances while those with low efficacy attribute failures to low levels of ability (e.g., Bandura, 1997; Silver, Mitchel \& Gist, 1995; Schunk \& Zimmerman, 1994). Extensive research findings also support the contention that efficacy is one of the strongest predictors of future action (Bandura, 1986; Cousins \& Walker, 2000; Pajares \& Schunk, 2002), whereas research clearly indicates that perceived knowledge may drastically deviate from actual knowledge (Cunningham et al., 2009). Therefore, the authors considered it more critical to examine one's knowledge and efficacy than to study one's attributions and efficacy.

The TCM is also unique from the EBCM and the other models because it examines efficacy at the behavior-specific level. Bandura (1997) recommended that efficacy be studied at the most specific level possible as an individual's efficacy may differ between tasks. With regard to teacher motivation, the TCM examines teachers' perceptions of innovation-specific efficacy. Generally, teacher efficacy is the self-reflective judgment of one's ability to influence or bring about valued student outcomes, regardless of student or environmental attributes (Tschannen-Moran, Hoy, \& Hoy, 1998, 2001). Examining efficacy at this general level is not revealing enough with regard to adopting a specific innovation. For example, a teacher may have high global or teacher efficacy, but report low efficacy for DDDM. Therefore, the TCM considers innovation-specific efficacy.

\section{Triadic Change Model}

The TCM assesses the likelihood of an individual adopting a new behavior by examining underlying obstacles to change and known predictors of future behaviors: knowledge about the innovation, innovation-specific efficacy, and concerns regarding the innovation. While the TCM is intended to apply to the adoption of new innovations in the context of organizational change, it is important to note that the current research focused on the application of the TCM to in-service teacher adoption of DDDM practices. The information gleaned from the TCM was used to evaluate and drive PD and facilitate the development of a data-literate faculty prepared to engage in classroom-level DDDM. The following discussion and research reflects this caveat.

Knowledge is a key component of teacher adoption of DDDM practices and the TCM. Unfortunately, K-12 educators are often entrenched in a system in which decisions are primarily based on intuition and hindsight rather than on empirical evidence such as student data (Cromey, Van der Ploeg, \& Masini, 2000; Schildkamp \& Kuiper, 2010). This instructional paradigm is difficult to surmount as many teachers also lack the requisite training to understand, analyze, and connect data to classroom practice (Creighton, 2007; Kerr et al., 2006). For example, in schools identified as innovative data users, only 19 percent of teachers and school leaders felt they had the requisite knowledge and abilities to manipulate data in meaningful ways (Supovitz \& Klein, 2003). Thus, it is important to better understand teacher knowledge levels in order to carefully craft PD to meet and develop teachers' DDDM-related needs and skills.

An additional and related component of the TCM is teacher concerns. With regard to the current work, concerns were defined as a set of feelings, perceptions, preoccupations, considerations, satisfactions, and frustrations related to adopting district desired DDDM practices (George et al., 2006). Concerns were selected for inclusion in the TCM and the current work based upon evidence from thirty years of research that indicates teacher concerns are predictive of future practice and a powerful tool for facilitating change (George et al., 2006).

For the purposes of this study, the authors also examined teacher efficacy specifically related to DDDM efficacy. DDDM efficacy reflects teachers' beliefs in their ability to successfully engage in DDDM (Airola, Dunn, \& Garrison, 2011). Similar to concerns, research indicates that efficacy is both a powerful predictor of future teacher action and a trainable teacher characteristic (Cousins \& Walker, 2000; Pajares \& Schunk, 2002). Thus, teacher efficacy serves as a cornerstone in teacher research and the TCM. There is a limited body of research that examines the role of efficacy in DDDM, but initial findings do indicate that teachers' lack confidence in their DDDM abilities (Dunn et al., 2011; Mason, 2002; Supovitz \& Klein, 2003).

One proposition of the TCM is that knowledge, concerns, and efficacy are interlocking determinants of one another, abiding in the context of mutual influence (See Figure 1). Research supports the relationship of the variables to one another, but no existing research was found that explored the collective influence or the mutual relationship of all three constructs. However, a great deal of research supports the assertion that knowledge is predictive of teacher efficacy (e.g., Raudenbush, Bhumirat, \& Kamali, 1992; Sarikaya, Cakiroglu, \& Tekkaya, 2005). Research also indicates that as teachers' efficacy levels increase, they are more likely to report higher level concerns,

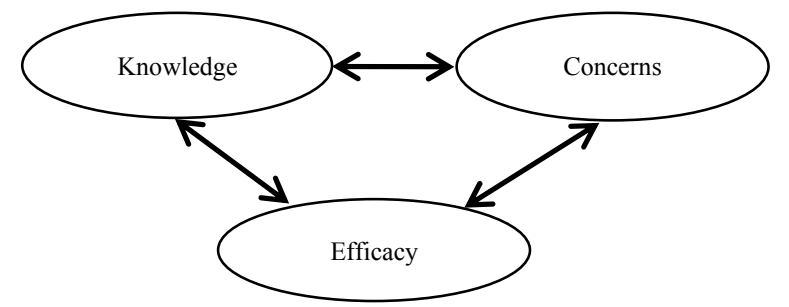

Figure 1.

Representation of TCM interlocking determinants. 
which are indicative of engagement in target behaviors (Dunn, 2008; Dunn \& Rakes, 2011; McKinney, Sexton, \& Meyerson, 1999).

Additionally, the TCM is unique in that, in lieu of a stagelike theory consisting of qualitatively different stages of development, it was designed to examine change in terms of gradual, quantitative changes, allowing for the natural ebb and flow of each of the three components within the proposed self-system while still acknowledging the developmental and progressive nature of the change process. Based on what one learns by examining teacher characteristics through the lens of this model, one may predict behavior and appropriately adjust PD practices. Therefore, this model served as the theoretical foundation for the development of the assessment framework use in this study.

\section{Methods}

The purpose of the qualitative portion of this research was to evaluate teacher adoption of DDDM using a TCM-based assessment framework in order to identify a profile that described teachers in the early stages of the change process associated with DDDM. The concept of an assessment framework was adopted from the literature in cognitive psychology and other science-based fields in which multiple quantifiable factors or measure outcomes are utilized to identify those at high, moderate, and low risk for various conditions or issues (Aumann, 2011). Instead of identifying risk, the TCM assessment framework was intended to aid in the identification of teacher status in the change process associated with adopting new innovations.

\section{Participants}

Participants in this study were teachers in a northwestern state in which statewide DDDM PD had been implemented for one academic year. PD included multi-day training seminars as well as job embedded training. The total number of participants was 2,582; of these, 1,579 respondents were included in the evaluation of the Reluctant-Avoidant Profile. The ReluctantAvoidant Profile sample was predominantly female $(\mathrm{n}=1,074$, $68 \%$ ). The profile consisted of 216 participants age 20-29 (19\%), 281 age $30-39(25 \%), 281$ age $40-49(25 \%), 301$ age $50-59(26 \%)$, and 60 age 60 or older (5\%). Due to union regulations designed to protect teachers, no other demographic data could be collected.

\section{Procedure}

The TCM framework assessment included three measurement instruments: SoCQ, the DDDM Efficacy (3D-ME) survey, and a DDDM knowledge test. Teachers were contacted by email and responded electronically to the three instruments. Teacher responses were aggregated by district. Sixty district profiles were represented graphically. The researchers evaluated the 60 district profiles. Of the 60 district profiles, 25 districts were identified as sharing commonalities across all three constructs. The responses of the teachers in those 25 districts were aggregated to produce the Reluctant-Avoidant Profile.

\section{Instruments}

A knowledge test that assessed teachers' knowledge levels related to analyzing and interpreting data as well as the connec- tion of data to classroom decision-making was used. The test was designed specifically to assess teacher knowledge garnered from their DDDM PD. Three content experts examined the knowledge test and reached consensus on the content validity of the items. The knowledge assessed included general DDDM knowledge and skills within the context of this state's PD curriculum. The test consisted of two portions, each of which reflected the two skill sets of a data-literate faculty (Stiggins, 2001). Part I of the knowledge test assessed teachers' ability to interpret and evaluate data. Part II assessed teachers' ability make instructional decisions using data. Examples of items are presented in Table 1.

Two surveys were also used for this research: the SoCQ and the 3D-ME. The SoCQ assessed the intensity of teacher concerns and consisted of 35-items and a seven-point Likert scale. The seven scales assessed the seven Stages of Concern (George et al., 2006; Hall \& Hord, 1987). Internal consistencies were deemed acceptable; Chronbach's alpha for each scale was as follows: Unconcerned $(\alpha=.60)$, Informational $(\alpha=.76)$, Personal $(\alpha=.80)$, Management $(\alpha=.64)$, Consequence $(\alpha=.60)$, Collaboration $(\alpha=.80)$, and Refocusing $(\alpha=.71)$. Chronbach's alpha was used to assess the internal consistency, and Nunnally's (1967) cutoff criterion of .60 was utilized. For this study, internal consistency was acceptable for each of the scales $(\alpha$ $=.60, .66, .80, .76, .61, .80, .71$, scales $0-6$ respectively). Examples of items designed to assess each stage are presented in Table 2.

The 3D-ME was developed and validated by the authors to assess teachers' DDDM efficacy (Airola et al., 2011; Dunn, Airola, Lo, \& Garrison, 2013a, 2013b). The measure included 22 -items on a five-point Likert scale and consists of four subscales: 1) Efficacy for data access and report selection, 2) Efficacy for use of data tools and technology, 3) Efficacy for data interpretation, evaluation and application, and 4) DDDM anxiety. In the original validation study, internal consistencies were deemed acceptable, $\alpha=.83, .91, .93$, and .89 , respectively (Airola et al., 2011). Internal consistency scores were similar for this study and were deemed acceptable for the four scales ( $\alpha$ $=.84, .91, .92, .89$, respectively).

The first scale, assessed teachers' confidence in the critical skill Stiggins (2001) described as the data-literate ability to access and gather dependable, high-quality student data (example item: I am confident in my ability to access state assessment results for my students. The second scale, efficacy for use of data tools and technology, is a related but separate ability. States now have complex data technology resources for teachers, and this scale assesses teachers' confidence in their ability to successfully utilize those technology resources (example item: I am confident I can use the tools provided by my district's data technology system to retrieve charts, tables, or graphs for analysis). The third scale, efficacy for data interpretation, evaluation, and application, assessed teachers' confidence in the second component Stiggins (2001) described as necessary to data-literacy - the ability to effectively use data to amplify student achievement (example item: I am confident that I can use data to identify students with special learning needs). Finally, the fourth scale, DDDM anxiety, is an inverse indicator of general DDDM efficacy (example item: I am intimidated by the process of connecting data analysis to my instructional practice). Several studies support the inverse relationship of efficacy and anxiety (e.g., Aydin, Uzuntiryaki, \& Demirdogen, 2011; Gresham, 2009). 


\section{K. E. DUNN ET AL.}

Table 1.

Knowledge test item examples.

\begin{tabular}{|c|c|c|}
\hline $\begin{array}{l}\text { Knowledge } \\
\text { Measure }\end{array}$ & Item & $\begin{array}{l}\text { Answer } \\
\text { Options }\end{array}$ \\
\hline Part I & $\begin{array}{l}\text { When evaluating classroom } \\
\text { assessments, one of the most } \\
\text { important considerations is validity, } \\
\text { because you can be confident that: }\end{array}$ & $\begin{array}{l}\text { A) The test scores give consistent information every time the test is administered. } \\
\text { B) The test was designed to measure what you want to measure. } \\
\text { C) The test matches your grade level. } \\
\text { D) The test is long enough to give you good information }\end{array}$ \\
\hline Part II & $\begin{array}{l}\text { Using tests to clarify the } \\
\text { curriculum is different from } \\
\text { teaching to the test when: }\end{array}$ & $\begin{array}{l}\text { A) Teachers use items from the test to determine their instructional curriculum. } \\
\text { B) Teachers use the results of assessment to understand the cognitive demand of the grade level standards. } \\
\text { C) Teachers use the test results to build identical items for teacher-made tests. } \\
\text { D) Teachers use test preparation materials to provide students with a variety of questions just like the test. }\end{array}$ \\
\hline
\end{tabular}

Note: ${ }^{*}$ Correct answer.

Table 2.

SoCQ item examples.

\begin{tabular}{|c|c|}
\hline Stage of Concern & Item \\
\hline Unconcerned & I spend little time thinking about the innovation. \\
\hline Informational Concerns & I would like to discuss the possibility of using data driven classroom decision-making. \\
\hline Personal Concerns & I would like to know how my teaching or administration is supposed to change. \\
\hline Management Concerns & I am concerned about my inability to manage all that data driven classroom decision-making requires. \\
\hline Consequence Concerns & I am concerned about how data driven classroom decision-making affects students. \\
\hline Collaboration Concerns & I would like to help other faculty in their use of data driven classroom decision-making. \\
\hline Refocusing Concerns & I know of some other approaches that might work better. \\
\hline
\end{tabular}

\section{Analysis}

The following methodology was used in this study. First, the authors created teacher profiles by analyzing the results of the knowledge test, SoCQ, and 3D-ME. Using descriptive statistics, the results were depicted in graphic form for the 60 school districts and evaluated for commonalities. The authors independently identified one common pattern shared by 25 districts. This shared profile was identified as the Reluctant-Avoidant Profile an interpreted in alignment with the TCM. Descriptive statistics were used to develop the profiles from the TCM assessment framework, and then qualitative techniques were utilized to identify commonalities in the profiles. The analyses for each measure are described below.

\section{Knowledge Test}

Knowledge measure scores were calculated by determining the number of items answered correctly. An initial representative sample was used to establish norms for raw score to a percentile rank conversion table. Raw scores for participants were converted to percentile ranks and reported numerically and graphically and then analyzed based upon the following criteria. Scores were interpreted as high if they exceeded $80^{\text {th }}$ percentile rank, moderate if they ranged from $50^{\text {th }}$ to the $79^{\text {th }}$ percentile rank, or low if they were at or below the $49^{\text {th }}$ percentile rank. The mean score for the group was computed and converted to a percentile.

\section{SoCQ}

To score the SoCQ, the sums of the five responses that correspond to each of the seven subscales on the SoCQ were calculated to provide a raw score for each subscale. Mean scores for each item were converted to percentile rank to illustrate the relative intensity of each stage of concern for the entire sample. The percentile ranks were reported numerically and graphically and analyzed based on guidelines outlined by George and his colleagues (2006).

\section{D-ME}

In order to categorize 3D-ME subscale scores as low, moderate, and high efficacy, the authors used the following criteria. A score was considered low if the scale mean was less than the mean and less than one standard deviation from the norming group mean, moderate if the scale mean was equal to or within one standard deviation of the norming group mean, or high if the scale mean was more than one standard deviation above the norming group mean (Airola et al., 2011).

\section{Results}

\section{Knowledge Test}

For respondents in the Reluctant-Avoidant Profile group, teacher knowledge was identified as low for Part I and Part II, $25^{\text {th }}$ percentile rank and $30^{\text {th }}$ percentile rank respectively (See Figure 2). Means and standard deviations for both the total sample and the Reluctant-Avoidant Profile are presented in Table 3.

\section{SoCQ}

To analyze participants' responses to the SoCQ, raw scores were converted to percentile rank and graphically represented following the procedures outlined by George et al. (2006). The means and standard deviations of the total sample and the 
Table 3.

Means and standard deviations for the knowledge measure.

\begin{tabular}{ccccccc}
\hline & \multicolumn{3}{c}{ All } & & \multicolumn{3}{c}{ Reluctant-Avoidant } \\
\hline $\begin{array}{c}\text { Knowledge } \\
\text { Measure }\end{array}$ & M & SD & Percentile & M & SD & Percentile \\
\hline Part I & 4.31 & 1.53 & 25 & 4.19 & 1.53 & 37 \\
Part II & 10.20 & 4.18 & 25 & 9.87 & 4.15 & 30 \\
\hline
\end{tabular}

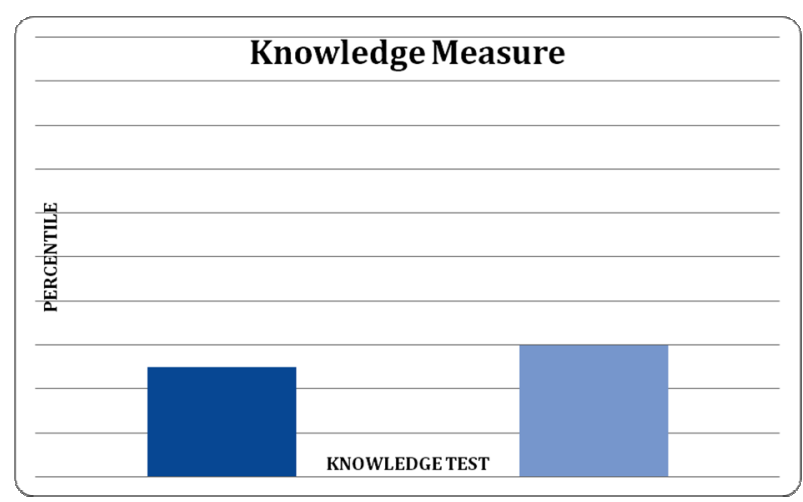

Figure 2.

Reluctant-Avoidant Profile: knowledge measure results.

Reluctant-Avoidant Profile group are presented in Table 4. Figure 3 provides a graphic representation of the ReluctantAvoidant SoCQ Profile.

The Stages of Concern profile in Figure 3 represented a description of the aggregate Reluctant-Avoidant Profile identified by the researchers' evaluation of the results of the overall assessment framework. In this Stages of Concern profile, teachers manifested a peak at Unconcerned Stage 0 and Refocusing Stage 6. The profile also presented a tailing up at Refocusing Stage 6 and a negative one-two split in which Personal Stage 2 concerns were higher than Information Stage 1 concerns. This profile supported a technical user profile (peak at Stage 0 and Stage 6) in which teachers are resistant to the implementation of DDDM practices (tailing up at Stage 6 and negative one-two split), were possibly unconcerned with DDDM or more concerned about other issues (peak at Stage 0), and are merely going through the motions of engaging in DDDM practices. Additionally, the teachers' profile also manifests a lesser but still important rise at Consequence (Stage 4), indicating that they were concerned about how their engagement in DDDM may impact students (George et al., 2006).

\section{D-ME}

The results of the 3D-ME were also analyzed and depicted graphically. After reviewing the means and standard deviations of the four scales and comparing them to the norming group, Reluctant-Avoidant Profile DDDM efficacy was determined to be moderate for all four of the 3D-ME scales. The means and standard deviations of the total sample and the ReluctantAvoidant Profile are presented in Table 5 and Figure 4 respectively.

\section{Reluctant-Avoidant Profile}

After profiles consisting of knowledge, concerns, and efficacy
Table 4.

Means, standard deviations, and percentiles for the SoCQ.

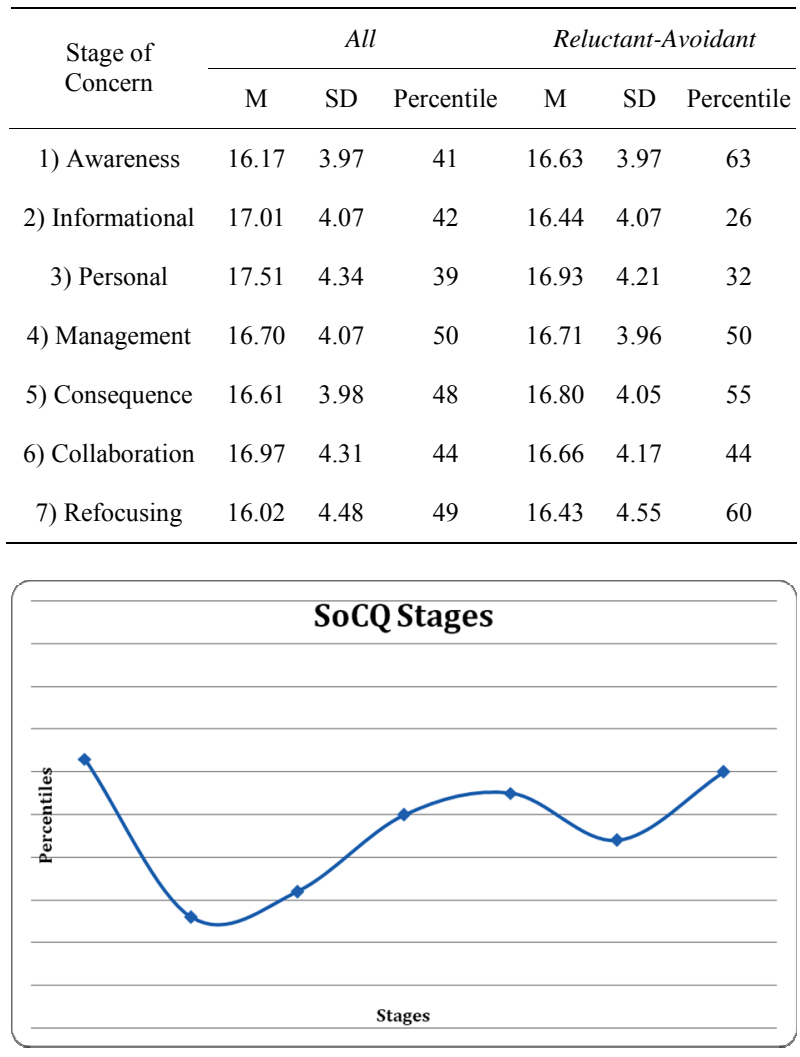

Figure 3.

Reluctant-Avoidant Profile: stages of concern results.

Table 5.

Means and standard for the 3D-ME.

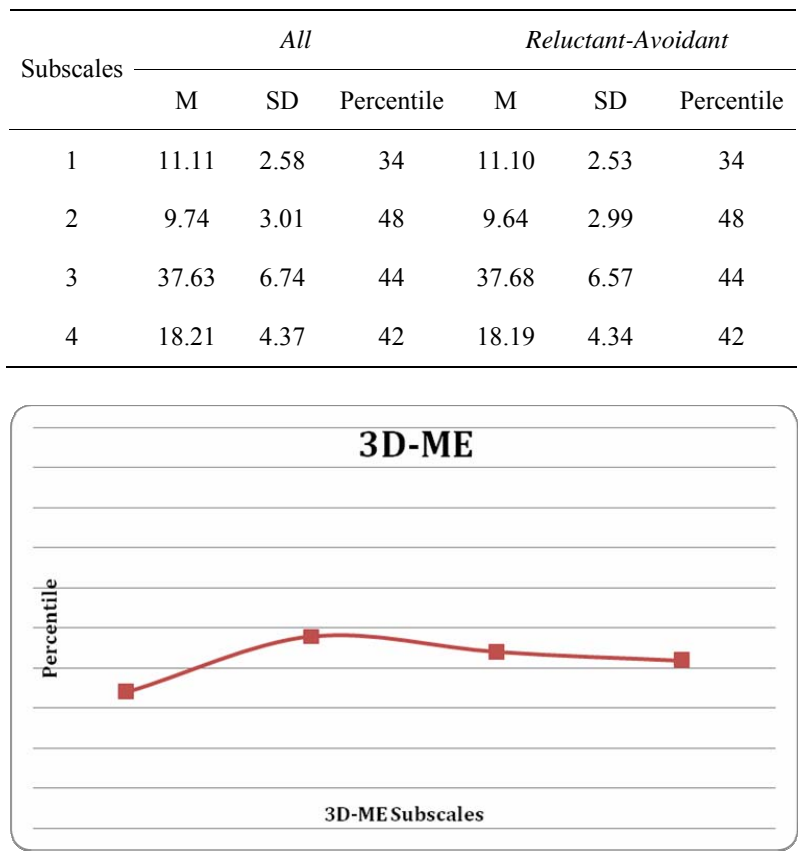

Figure 4.

Reluctant-Avoidant Profile: DDDM efficacy results. 
were created for each of the 60 school districts, the authors independently examined the profiles to identify commonalities across profiles. Of the 60 profiles examined, 25 were independently and unanimously grouped together. The authors interpreted this profile as one that described those who were resistant to DDDM and reluctant to engage in DDDM, and thus labeled the Reluctant-Avoidant Profile. The shared characteristics of the Reluctant-Avoidant Profile identified by the authors are discussed below.

The Reluctant-Avoidant Profile's SoCQ results reflected a concerns profile in which the teachers were going through the motions of the district-desired practices as per the peaks at Stage 0 and Stage 6. They were exploring alternative courses of action, and may have believed they knew of more effective practices (George et al., 2006). In part, this profile was defined as reluctant and avoidant because of two concerns characteristics - a negative one-two split (Stage 2 higher than Stage 1) and the tailing-up (Stage 6 higher than Stage 5). The negative one-two split and the tailing-up (Stage 6 higher than Stage 5) indicated that these teachers may have doubted the effectiveness of the innovation and they were resistant to adopting the innovation, in fact, this extreme tailing-up "should be heeded as an alarm" (George et al., 2006: p. 42). The peak at Stage 0 further supported the reluctant-avoidant interpretation.

Additionally, the Reluctant-Avoidant Profile included moderate levels of efficacy indicating these teachers were fairly confident in their ability to engage in DDDM practices. These teachers also reported moderate levels of DDDM anxiety further supporting the interpretation of this group of teachers as reluctant and avoidant with regard to DDDM. Finally, the respondents who fell into the Reluctant-Avoidant Profile reported low levels of knowledge related to DDDM. Thus, ReluctantAvoidant teachers were reported greater confidence in their abilities for DDDM than their actual knowledge supported.

The remaining profiles shared some of the qualities of what the authors titled the Reluctant-Avoidant Profile, but lacked a complete match with the Reluctant-Avoidant Profile and did not share sufficient unique characteristics with other profiles to warrant categorization into a separate profile. For example, nine profiles reflected moderate efficacy, but reported knowledge levels that ranged from low to moderate and a concerns profile that indicated they were primarily concerned about how the new innovation will impact them. Four of the aforementioned nine profiles presented a tailing-up in their SoCQ profile, which indicates resistance to the target innovation (George et al., 2006). Six other profiles reported moderate to low efficacy, low knowledge, but failed to manifest an interpretable SoCQ profile, which may result when a great deal of diversity in responses occurs, masking results. The remaining profiles share too few similarities with one another to be considered for grouping.

\section{Discussion}

The findings of this study, viewed through the interpretative lens of the TCM, align with Ingram and her colleagues (2004) finding that teachers do not yet fully trust or use data to drive instructional decision-making. In the Reluctant-Avoidant Profile, teacher responses to the SoCQ supported what is technically a User Profile; however, they are more or less going through the motions as indicated by the spike at Stage 0 and Stage 6 (George et al., 2006). The peak at Stage 0, Unconcerned, indicated that these teachers believed other things are more important than DDDM. The peak at Stage 6, Refocusing Concerns, indicated that while these teachers may have been going through the motions of DDDM to satisfy school leaders, they were exploring alternative courses of action they believed had more value than current DDDM practices promoted by the state's department of education. Moreover, the negative-one two split and the tailing-up indicated that these teachers may have doubted the effectiveness of the innovation and they were resistant to adopting the innovation.

Additionally, teachers' concerns steadily increased from Personal Concerns to Consequence Concerns. Thus, teachers held some concerns about the impact DDDM may have on them, but were more concerned about the impact DDDM will have on students. When considered in conjunction with the peaks at Stage 0 and Stage 6, it may be that concerns for how DDDM will impact students influenced reluctance to DDDM and serious consideration of other practices.

As a result, it will be important to discover what teachers view as more viable alternatives to DDDM in order to create persuasive, appropriate, and effective training. By applying the metaphor of teaching as persuasion (Murphy, 2001) to PD efforts, trainers can unearth misconceptions teachers may hold about DDDM or about the practices they perceive as inherently more valuable than DDDM. Using this approach, trainers will provide teachers with opportunities to discuss what other courses of action they view as having more value than DDDM, and subsequently, trainers address any misconceptions or misunderstandings (Murphy, 2001).

An example of a common misconception teachers hold is that two different scales are equal or comparable. For example, teachers may compare English Language Arts (ELA) scores and Math scores from a state-mandated test without understanding the parameters of the scaled score. By relying on intuition, teachers may assume that a large increase in ELA scores from a previous year indicates that students had greater gains when compared to a small increase in Math scores. However, if the statistical characteristics of the scale were better understood, teachers may find that the seemingly small increase on Math scores was more meaningful than the large gains in ELA scores. Teachers who make this mistake may lose faith in DDDM, as it does not align with what they see in their students, or they may make incorrect decisions on what is most important to address in their classrooms. Once these types of misconceptions are understood, PD efforts may correct misunderstandings and integrate evidence that supports the effectiveness of DDDM.

It may also be the case that these teachers held beliefs that may complement and work in tandem with DDDM. For example, many teachers believe that the phrase DDDM only alludes to state-mandated summative assessments, and that formative assessments are superior to DDDM (Anderson, Leithwood, \& Strauss, 2010). In this case, PD would need to explain how both formative assessment and summative assessment data may be used to improve student outcomes through DDDM. Whether teachers hold misunderstandings about DDDM or simply know of another practice they prefer to DDDM, PD efforts may be tailored to fit the results of an inquiry about what teachers believe DDDM is and what practices teachers believe hold more value than DDDM. Through targeted PD efforts, teachers may be persuaded to engage in more DDDM.

In addition to considering alternatives to DDDM, the Reluctant-Avoidant Profile teachers reported moderate levels on all four 3D-ME scales. It is important to address these teachers' 
DDME efficacy as efficacy indicates the likelihood of engagement in targeted practices (Pajares \& Schunk, 2002; Zimmerman, 2000). It is also important to note that these teachers scored moderately on DDDM anxiety. While anxiety is an inverse indicator of efficacy (Aydin et al., 2011; Gresham, 2009), a moderate level of anxiety may impede engagement in innovations (Learner \& Timberlake, 1995). Thus, teacher anxiety is a contributing factor to teacher resistance to DDDM and may be an impediment to these teachers engagement in DDDM.

PD activities should be designed to address and ameliorate teachers' DDDM anxiety. Research findings provide support for a variety of strategies that may reduce anxiety related to statistics. These strategies include instructor encouragement (Wilson \& Onwuegbuzie, 2001), the provision of coping strategies to students (Pan \& Tang, 2004), sensitivity and attentiveness to learners' needs (Pang \& Tang, 2005), the use of real world examples (Pang \& Tang, 2005), and the use of a humorous instructional style (Schacht \& Stewart, 1990; Wilson, 1998). As statistics are a critical component of DDDM, the application of these strategies to DDDM PD may reduce DDDM anxiety. Future research should investigate the influence of these practices on teachers' DDDM anxiety.

The Reluctant-Avoidant Profile included low scores on both components of the knowledge measure. This indicated that teachers did not possess the requisite knowledge to effectively or accurately engage in DDDM. Thus, it will be important to build, expand, and deepen the knowledge base of those who reported a Reluctant-Avoidant Profile. This will serve to strengthen teacher efficacy (Scherer \& Bruce, 2001) and facilitate higher-level concerns (Zielinski \& Bernardo, 1989) as well as more successful DDDM.

Moreover, the disparity between efficacy and knowledge is of great importance when considered with the technical user concerns profile. Essentially, these teachers are more confident in their abilities and knowledge related to DDDM than their skills and knowledge support. Thus, if they are engaging in DDDM it is likely ineffective (Raudenbush et al., 1992). Furthermore, teachers are making judgments about practices they believe are superior to DDDM without fully understanding how to engage in DDDM. The application of the teaching as persuasion metaphor in PD may also amend this situation by revealing and addressing inadequate understanding.

The synergistic evaluation of the TCM assessment framework revealed that teachers who fit the Reluctant-Avoidant Profile are only engaging in DDDM practices at a superficial level. The teachers lack the necessary knowledge base and confidence needed to engage in effective DDDM as promoted by the state and the district. By increasing teacher knowledge and efficacy, it is likely that a true user concerns profile may manifest (Boz \& Boz, 2010; Charalambos, Philippou, \& Kyriakides, 2004).

Direct instruction related to DDDM practices will concurrently build the needed knowledge base and increase related forms of efficacy, as research indicates a link between motivational beliefs and knowledge acquisition (Bruning, Schraw, \& Ronning, 1999; Chuang, Liao, and Tai, 2005). Peer modeling is another powerful tool that serves to increase both knowledge and confidence (Bandura, 1997; Latham, Millman, \& Miedema, 1998). Direct knowledge instruction and peer modeling may both serve to increase knowledge and efficacy (Bruning et al., 1999; Chuang et al., 2005), and subsequently encourage teachers to higher level concerns (Dunn \& Rakes, 2011) and en- gagement in classroom-level DDDM. Additionally, if teachers are provided the opportunity to apply what they learn in PD training at a level where they will experience success and immediate reinforcement (however not so low a level as to seem patronizing) (Locke \& Latham, 1990), teacher DDDM efficacy should increase and likely lead to an increase in classroom DDDM. Future research should examine this chain of inferences.

It is critical that no one component of the TCM assessment framework be examined without taking into consideration the characteristics and influence of the other variables. For example in this profile, teacher knowledge related to DDDM was low. If one were to simply address low knowledge in order to facilitate adoption of DDDM, these teachers would likely continue to be resistant as indicated by the concerns profile. In the case of the Reluctant-Resistant Profile, trainers should first address teacher Refocusing and Personal Concerns as well as DDDM anxiety. Subsequently, teachers will likely be more open to learning about DDDM. Without an understanding of all the components of the TCM assessment framework as well as their shared influence, haphazardly addressing one of these variables without consideration of the others my cause teachers to become more entrenched in their reluctance and avoidance related to adopting DDDM. Thus, the strength of the TCM assessment framework lies in the gestalt of the mutual influence of the three components.

\section{Limitations}

The current study had a number of limitations. First, while the sample was large, generalizability was limited because a convenience sample from only one state in the US was used. Thus, future research should explore the outcome of the TCM assessment framework with teachers in the early stages of adoption of DDDM in other states and in other countries who also encourage evidence-based instruction. This study was also limited because teacher data could not be linked to student data. Thus, future research should explore the influence of the TCM profiles on student outcomes. Also, this study only explored the early stages of the change process associated with teacher adoption of DDDM. Future research should explore the full change process from introduction to DDDM to full integration of DDDM in the instructional process. Although the study was limited in a variety of ways, it was an important first step toward better understanding the change process associated with teacher adoption of DDDM practices.

\section{Conclusion}

After a decade of investing in PD intended to facilitate teacher engagement in DDDM in the US and beyond, the TCM assessment framework may provide a useful tool for meeting the goal of a data driven decision-maker in every classroom. The results garnered from the TCM assessment framework may help trainers in the US and abroad to interpret the impact of PD on teachers and derive suggestions for improving PD from the existing research base associated with teacher concerns, efficacy, and knowledge. By using data to drive PD efforts, tailored PD efforts may yield more desirable results-teacher DDDM and improve student outcomes. Finally, it is important to note that if states and districts utilize assessment frameworks to assess teacher data and to connect that data to the development of targeted PD efforts, they will model the actions in 
which they want their teachers to engage. The result is a simple application of another metaphor for teaching-Practice what you preach.

\section{REFERENCES}

Airola, D. T., \& Dunn, K. E. (2011). Oregon DATA project final evaluation report. Fayetteville, AR: Next Level Evaluation, Inc. http://oregondataproject.org/files/data.k12partners.org/2011-0909_Fi nalStateReport.docx

Airola, D., Dunn, K. E., \& Garrison, M. (2011). 3D-ME: The validation of the Data Driven Decision-Making Efficacy questionnaire. Washington, DC: the American Psychological Association Convention.

Ajzen, I. (1991). The theory of planned behavior. Organizational Behavior and Human Decision Processes, 50, 179-211. http://dx.doi.org/10.1016/0749-5978(91)90020-T

Anderson, S., Leithwood, K., \& Strauss, T. (2010). Leading data use in schools: Organizational conditions and practices at the school and district levels. Leadership and Policy in Schools, 9, 292-327. http://dx.doi.org/10.1080/15700761003731492

Aumann, C. A. (2011). Constructing model credibility in the context of policy appraisal. Environmental Modeling and Software, 26, 258-265. http://dx.doi.org/10.1016/j.envsoft.2009.09.006

Aydin, Y. C., Uzuntiryaki, E., \& Demirdogen, B. (2011). Interplay of motivational and cognitive strategies in predicting self-efficacy and anxiety. Educational Psychology, 31, 55-66.

http://dx.doi.org/10.1080/01443410.2010.518561

Bandura, A. (1997). Self-efficacy: The exercise of control. New York: W. H. Freeman and Company.

Bandura, A. (1986). Social foundations of thought and action: A social cognitive theory. Englewood Cliffs, NJ: Prentice-Hall.

Bandura, A. (1978). The self system in reciprocal determinism. American Psychologist, 33, 343-358. http://dx.doi.org/10.1037/0003-066X.33.4.344

Beck, J., Czerniak, C. M., \& Lumpe, A. T. (2000). An exploratory study of teachers' beliefs regarding the implementation of constructivism in their classrooms. Journal of Science Teacher Education, 11, 323-343. http://dx.doi.org/10.1023/A:1009481115135

Bernhardt, V. L. (2009). Data use: Data-driven decision making takes a big-picture view of the needs of teachers and students. Journal of Staff Development, 30, 24-27.

Boz, Y., \& Boz, N. (2010). The nature of the relationship between teaching concerns and sense of efficacy. European Journal of Teacher Education, 33, 279-291. http://dx.doi.org/10.1080/02619768.2010.490910

Bruning, R., Schraw, G., \& Ronning, R. (1999). Cognitive psychology and instruction. Upper Saddle River, NJ: Prentice Hall.

Carlson, D., Borman, G., \& Robinson, M. (2011). A multistate district-level cluster randomized trial of the impact of data-driven reform on reading and mathematics achievement. Educational Evaluation and Policy Analysis, 33, 378-398. http://dx.doi.org/10.3102/0162373711412765

Charalambos, C., Philippou, G., \& Kyriakides, L. (2004). Towards a unified model on teachers' concerns and efficacy beliefs related to mathematics reform. Proceedings of International Group for the Psychology of Mathematics Education, 2, 199-206

Chuang, A., Liao, W., \& Tai, W. (2005). An investigation of individual and contextual factors influencing training. Social Behavior and Personality, 33, 159-173. http://dx.doi.org/10.2224/sbp.2005.33.2.159

Cousins, B., \& Walker, C. (2000). Predictors of educators' valuing of systematic inquiry in schools. Canadian Journal of Program Evaluation, Special Issue, 25-52.

Creighton, T. B. (2007). Schools and data: The educator's guide for using data to improve decision-making (2nd ed.). Thousand Oaks, CA: Corwin Press.

Cromey, A., Van der Ploeg, A., \& Masini, B. (2000). The Call for Data-Driven Decision Making in the Midwest's Schools: NCREL's Response. Oak Brooks, IL: North Central Regional Educational
Laboratory.

Cunningham, A. E., Zibulsky, J., \& Callahan, M. D. (2009). Starting small: Building preschool teacher knowledge that supports literacy development. Reading and Writing, 22, 487-510. http://dx.doi.org/10.1007/s11145-009-9164-Z

Dembosky, J. W., Pane, J. F., Barney, H., \& Christina, R. (2005). Data driving decision-making in southwestern Pennsylvania school districts. Santa Monica, CA: RAND.

Dunn, K. E. (2008). The implementation of learner-centered principles: An analysis of preservice teacher beliefs and concerns. Doctoral Dissertation, ProQuest Dissertations and Theses, 3328225. http://search.proquest.com/docview/304576195?accountid=8361

Dunn, K. E.,Airola, D., Garrison, M., \& Nickens, B. (2011). Becoming data-driven: The influence of data-driven decision making efficacy beliefs on teachers' consequence concerns. Washington, DC: The American Psychological Association Convention.

Dunn, K. E., Airola, D. T., Lo, W., \& Garrison, M. (2013a). Becoming data-driven: Exploring teacher efficacy and concerns related to datadriven decision making. Journal of Experimental Education, 81, 222 241. http://dx.doi.org/10.1080/00220973.2012.699899

Dunn, K. E., Airola, D. T., Lo, W. J., \& Garrison, M. (2013b). What teachers think about what they can do with data: Development and validation of the data driven decision-making efficacy and anxiety inventory. Contemporary Educational Psychology, 38, 87-98. http://dx.doi.org/10.1016/j.cedpsych.2012.11.002

Dunn, K. E., \& Rakes, G. C. (2011). Teaching teachers: An investigation of beliefs in teacher education students. Learning Environments Research, 14, 39-58. http://dx.doi.org/10.1007/s10984-011-9083-1

Espin, C. A., McMaster, K. L., Rose, S. \& Wayman, M. M. (2012). A measure of success: The influence of curriculum-based measurement on education. Minneapolis, MN: University of Minnesota Press.

George, A. A., Hall, G. E., \& Stiegelbauer, S. M. (2006). Measuring implementation in schools: The stages of concern questionnaire. Austin, TX: Southwest Educational Development Laboratory.

Gresham, G. (2009). An examination of mathematics teacher efficacy and mathematics anxiety in elementary pre-service teachers. Journal of Classroom Interaction, 44, 22-38.

Hall, G. E., George, A. A., \& Rutherford, W. L. (1979). Measuring Stages of Concern about the innovation: A manual for use of the SoC Questionnaire. Austin, TX: University of Texas.

Hall, G. E., \& Hord, S. M. (1987). Change in schools: Facilitating the process. New York: State University of New York Press.

Hall, G., \& Hord, S. (2011). Implementing change: Patterns, principles, and potholes (3rd ed.). Needham Heights, MA: Allyn and Bacon.

Hall, G. E., Wallace, R. C., \& Dossett, W. A. (1973). A developmental conceptualization of the adoption process within educational institutions. Austin, TX: University of Texas.

Ingram, D., Louis, K. S., \& Schroeder, R. G. (2004). Accountability policies and teacher decision making: Barrier to the use of data to improve practice. Teachers College Record, 106, 1258-1287. http://dx.doi.org/10.1111/j.1467-9620.2004.00379.x

Kerr, K. A., Marsh, J. A., Ikemoto, G. S., Darilek, H., \& Barney, H. (2006). Strategies to promote data use for instructional improvement: Actions, outcomes, and lessons from three urban districts. American Journal of Education, 112, 496-520. http://dx.doi.org/10.1086/505057

Learner, D. K., \& Timberlake, L. M. (1995). Teachers with limited computer knowledge: Variables affecting use and hints to increase use.

Latham, G. P., Millman, Z., \& Miedema, H. (1998). Theoretical, practical and organizational issues affecting training. In C. J. De Wolff, P. J. D. Drenth, \& H. Thierry (Eds.), A handbook of work and organizational psychology: Personnel psychology, Vol. 3 (pp. 185-207). East Sussex: Psychology Press, Ltd.

Locke, E. A., \& Latham, G. P. (1990) A theory of goal setting and task performance. Englewood Cliffs, NJ: Prentice-Hall.

Mandinach, E. (2011). Recent developments in how the field of educational psychology has contributed to educational policy debate and implementation. Washington, DC: The American Psychological Association Convention. 
Mason, S. (2002). Turning data into knowledge: Lessons from six Milwaukee public schools. Madison, WI: Wisconsin Center for Education Research.

McKinney, M., Sexton, T., \& Meyerson, M. J. (1999). Validating the efficacy-based change model. Teaching and Teacher Education, 15, 477-485. http://dx.doi.org/10.1016/S0742-051X(98)00051-1

Murphy, P. K. (2001). Teaching as persuasion: A new metaphor for a new decade. Theory into Practice, 40, 224-277. http://dx.doi.org/10.1207/s15430421tip4004 2

Nunnally, J. C. (1967). Psychometric theory. New York: McGraw-Hill.

Ohlhausen, M. M., Meyerson, M. J., \& Sexton, T. (1992). Viewing innovations through the Efficacy-Based Change Model: A whole language application. Journal of Reading, 35, 536-541.

Pajares, E., \& Schunk, D. H. (2002). Self and self-belief in psychology and education: A historical perspective. In J. Aronson (Ed.), Improving academic achievement impact of psychological factors on education (pp. 3-21). Amsterdam: Academic Press. http://dx.doi.org/10.1016/B978-012064455-1/50004-X

Pan, W., \& Tang, M. (2004). Examining the effectiveness of innovative instructional methods on reducing statistics anxiety for graduate students in the social sciences. Journal of Instructional Psychology, 31, 149-159.

Pan, W., \& Tang, M. (2005). Students' perceptions on factors of statistics anxiety and instructional strategies. Journal of Instructional Psychology, 32, 205-214.

Raudenbush, S. W., Bhumirat, C., \& Kamali, M. (1992). Predictors and consequences of primary teachers' sense of efficacy and students' perceptions of teaching quality in Thailand. International Journal of Educational Research, 17, 165-177. http://dx.doi.org/10.1016/0883-0355(92)90006-R

Samuel, M. (2008). Accountability to whom? For what? Teacher identity and the force field model of teacher development. Perspectives in Education, 26, 3-16.

Sarikaya, H., Cakiroglu, J., \& Tekkaya, C. (2005). Self-efficacy, attitude and science knowledge. Academic Exchange Quarterly, 9, 3842.

Schacht, S., \&Stewart, B. J. (1990). What's funny about statistics? A technique for reducing student anxiety. Teaching Sociology, 18, 5256. http://dx.doi.org/10.2307/1318231

Scherer, Y. K., \& Bruce, S. (2001). Knowledge, attitudes, and selfefficacy and compliance with medical regimen, number of emergency department visits, and hospitalizations in adults with asthma. Heart Lung, 30, 250-257. http://dx.doi.org/10.1067/mhl.2001.116013

Scheurich, J. J., \& Skrla, L. (2003). Leadership for equity and excellence: Creating high-achievement classrooms, schools, and districts. Thousands Oaks, CA: Corwin Press.

Schildkamp, K., \& Kuiper, W. (2010). Data-informed curriculum reform: Which data, what purposes, and promoting and hindering factors. Teaching and Teacher Education, 26, 482-496. http://dx.doi.org/10.1016/j.tate.2009.06.007

Schunk, D. H., \& Zimmerman, B. J. (1994). Self-regulation of learning and performance: Issues and educational applications. Hillsdale, NJ: Erlbaum.

Silver, W. S., Mitchel, T. R., \& Gist, M. E. (1995). Responses to successful and unsuccessful performances: The moderating effect of self-efficacy on the relationship between performance and attributions. Organizational Behavior and Human Decision Processes, 62, 286-299. http://dx.doi.org/10.1006/obhd.1995.1051

Stiggins, R. J. (2001). Student-involved classroom assessment (3rd ed.). Upper Saddle River, NJ: Prentice Hall.

Supovitz, J. A., \& Klein, V. (2003). Mapping a course for improved student learning: How innovative schools systematically use student performance data to guide improvement. Report, Philadelphia, PA: Consortium for Policy Research in Education.

Sztajn, P. (2003). Adapting reform ideas in different mathematics classrooms: Beliefs beyond mathematics. Journal of Mathematics Teacher Education, 6, 53-75. http://dx.doi.org/10.1023/A:1022171531285

Tschannen-Moran, M., Hoy, A. W., \& Hoy, W. K. (1998). Teacher efficacy: Its meaning and measure. Review of Educational Research, 68, 202-248. http://dx.doi.org/10.3102/00346543068002202

Tschannen-Moran, M., \& Hoy, A. W. (2001). Teacher efficacy: Capturing an elusive construct. Teaching and Teacher Education, 17, 783-805. http://dx.doi.org/10.1016/S0742-051X(01)00036-1

Wayman, J. C. (2005). Involving teachers in data-driven decisionmaking: Using computer data systems to support teacher inquiry and reflection. Journal of Education for Students Placed At Risk, 10, 295 308. http://dx.doi.org/10.1207/s15327671espr1003 5

Wayman, J. C., \& Stringfield, S. (2006). Technology-supported involvement of entire faculties in examination of student data for instructional improvement. American Journal of Education, 112, 549571. http://dx.doi.org/10.1086/505059

Wilson, V. A. (November 1998). A study of reduction of anxiety in graduate students in an introductory educational research course. New Orleans, LA: The Annual Meeting of the Mid-South Educational Research Association.

Wilson, V. A., \& Onwuegbuzie, A. J. (2001). Increasing and decreasing anxiety: A study of doctoral students in educational research courses. Little Rock, AR: The Annual Meeting of the Mid-South Educational Research Association.

Zielinski, E. J., \& Bernardo, J. A. (1989). The effects of a summer inservice program on secondary science teachers' Stages of Concern, attitudes, and knowledge of selected STS concepts and its impact on students' knowledge. San Francisco, CA: The National Association for Research in Science Teaching.

Zimmerman, B. J. (2000). Self-efficacy: An essential motive to learn. Contemporary Educational Psychology, 25, 82-91.

http://dx.doi.org/10.1006/ceps.1999.1016 